\title{
Prenatal Risk Factors on Children's Cerebral Palsy Case at RSIA Bunda Jakarta
}

\author{
Banatul Lariza $^{1(\mathbb{D})}$, Kurnia Dwi Artanti ${ }^{*}{ }^{\mathbb{D}}$, Taufiq Hidayat $^{3(\mathbb{D})}$ \\ ${ }^{1}$ Faculty of Public Health, Universitas Airlangga, Surabaya, Indonesia \\ ${ }^{2}$ Department of Epidemiology, Faculty of Public Health, Universitas Airlangga, Surabaya, Indonesia \\ ${ }^{3}$ Departement of Paediatrics, Kulliyyah of Medicine, International Islamic University Malaysia, Kuantan, Malaysia
}

\section{A R T I C L E I N F O}

\section{Article history:}

Received 11 June 2021

Received in revised form 2 August 2021

Accepted 30 August 2021

Available online 31 October 2021

\section{Keywords: \\ Birth Complication, \\ Cerebral Palsy, \\ Maternal Health, \\ Prenatal Risk.}

*) Corresponding author:
kurnia-d-a@fkm.unair.ac.id

\begin{abstract}
A B S T R A C T
Introduction: Cerebral Palsy is a disease that is less recognized by the public due to the lack of information related to $\mathrm{CP}$ in Indonesia. Aims to analyze prenatal risk factors that influence the evidence of CP RSIA Bunda Jakarta.

Methods: This study was conducted in April 2021 at RSIA Bunda Jakarta, an analytical study with a case control design. The sample in this study were 124 respondents from mothers of children who underwent outpatient treatment at the RSIA Bunda Jakartaas cases and controls. each taken by simple random sampling technique. Data were analyzed using the test chi-square to analyze the relationship between variables.

Results: The results of statistical analysis showed that the risk factors associated with the incidence of $\mathrm{CP}$ were maternal age $(\mathrm{p}=0.00 ; \mathrm{OR}=13.25 ; 95 \% \mathrm{CI}=2.93-59.93)$, preeclampsia $(\mathrm{p}=0.00 ; \mathrm{OR}=$ $2,06 ; 95 \% \mathrm{CI}=1,71-2,48), \mathrm{TORCH}(\mathrm{p}=0.00 ; \mathrm{OR}=2.40 ; 95 \% \mathrm{CI}=1.92-3.01)$, and antenatal care $(\mathrm{p}=$ $0.00 ; \mathrm{OR}=41.2 ; 95 \% \mathrm{CI}=5.45-317.0)$.

Conclusion: Risk factors affecting the occurrence of $\mathrm{CP}$ in children include age $<20$ or $\geq 35$ years, preeclampsia, TORCH infection and antenatal care visits $<4$ times. It is necessary to increase intervention programs at various levels of health services to diagnose and prevent the occurrence of cerebral palsy in children so that optimal maternal and child health is achieved. and further research is needed to determine other risk factors that can cause $\mathrm{CP}$ in children such as perinatal and postnatal risk factors.
\end{abstract}

\section{Introduction}

Cerebral Palsy $(\mathrm{CP})$ is a term used for all chronic neurological disorders that manifest as impaired control of body movement and coordination. Children who suffer from $\mathrm{CP}$ are one of the children with special needs because they have abnormalities or disabilities due to brain damage and result in speech, hearing, vision, intelligence, social, emotional, behavioral disorders, impaired control of body movements and coordination. This chronic neurological disorder causes permanent disability if not treated promptly. ${ }^{1}$

In Indonesia, the overall prevalence of $\mathrm{CP}$ sufferers cannot yet be known however several researchers have recorded and presented the results Basic Health Research in 2010 stated that the percentage of children aged 24-59 months suffering from CP was $0.09 \%$ or $1-5$ per 1000 live births. ${ }^{2}$ Research conducted by a special needs children community in Semarang revealed that the number of children diagnose with CP increases every year, where in 2013 there were 47 children, in 2014 there were 50 children, in 2015 there were
56 children, and increased again in 2016 with 78 children. ${ }^{3}$ Based on research conducted at the Medical Rehabilitation Installation of Prof. Dr. R. D. Kandou Manado, there were 33 cases of $\mathrm{CP}$, with the highest distribution of $\mathrm{CP}$ patients aged $1-5$ years, namely 19 respondents or $(57.6 \%){ }^{4}$

Until now, the exact cause of CP is unknown and cannot be cured, but in general, therapy and treatment can be given to children with CP. Several studies suggest that the cause of CP is multifactorial. According to Sadowska et al., the cause can be divided into prenatal, perinatal, and postnatal. ${ }^{5}$ Based on research conducted by Puteri and Antasari at the Pediatric and Neurodevelopmental Therapy Center Growth Clinic, it is known that prenatal factors, perinatal factors, and postnatal factors affect CP growth by $(55.2 \%)$ while $(43.8 \%)$ other factors such as education, economic and environmental factors. ${ }^{1}$ Based on the risk factors for the incidence of $\mathrm{CP}$ at the Kity Center Clinic Jakarta, the results showed that most of the incidence of CP was caused by prenatal factors, namely 325 children (62\%), perinatal factors as many as 134 
children or by $(26 \%)$, and postnatal factors by 63 children or equal to $(12 \%)$ of the total 523 children. ${ }^{6}$ Similar results in another study shows of a total of 57 children with $\mathrm{CP}$ of $69.5 \%$ caused by prenatal factors, $55.7 \%$ postnatal factors and $33.4 \%$ due to perinatal factors. ${ }^{7}$ Given these differences, it is necessary to conduct a study to find out what are the risk factors for the incidence of CP in Indonesia, therefore the aim of this study is to evaluate the proportion of perinatal factors within the cause of CP cases at RSIA Bunda Jakarta.

\section{Methods}

This study was a cross sectional study conducted at Out clinic Patient of Department Dermatology and Venereology, Dr. Soetomo General Academic Hospital, Surabaya, Indonesia during period January-December 2017. The specimens were taken from patient after they sign the informed consent. Those who were not willing to participate in this study were excluded. This study was approved by the Medical Ethic Research from Dr. Soetomo General Academic Hospital Surabaya, number 382/Panke.KKE/V/2016.

The inclusion criteria of sample were all of patients diagnosed with condyloma acuminata using visual inspection by Dermatologist and willing to participate in this study by sign the informed consent. The exclusion criteria of patients were women in menstruation period or pregnant and cervicitis, women or men in infection HPV and AIDS.

There were 36 specimens of the biopsy tissues taken from lesion patient who diagnosed as condyloma acuminata. The specimen was separated become two sections; one section is for tissues processing in block paraffin as procedure for making histopathology diagnose. The histopathology diagnosed of condyloma acuminata performed by Expert Pathologist. The other section is for genotyping HPV.

The genotyping of HPV was performed by Polymerase Chain Reaction (PCR) and followed by reverse line blot assay. DNA virus was extracted from specimen of condyloma acuminata by using QIAamp DNA Mini Kit (Qiagen) and genotyping of HPV was using Ampliquality HPV type express v 3.0 (AB Analitica) according to the manufacture's protocol that identified 40 genotypes of HPV.

\section{Results}

From a total of 124 respondents, the majority were aged 2035 years when they were pregnant, $83.1 \%$. Did not experience preeclampsia and diabetes mellitus during pregnancy $96.8 \%$. Not suffering from TORCH during pregnancy $85.5 \%$. And antenatal care visits during pregnancy 4 times or more $79.0 \%$.

Table 1. Characteristic of Respondent

\begin{tabular}{lcc}
\hline \multicolumn{1}{c}{ Characteristic } & $\begin{array}{c}\text { Frequency } \\
(\mathbf{n = 1 2 4})\end{array}$ & Percentage \\
\hline Cerebral Palsy & & \\
\hline Yes & 62 & 50 \\
\hline No & 62 & 50 \\
\hline Pregnant Mother's Age & & \\
\hline $20-35$ years old & 103 & 83.1 \\
\hline$<20$ years or $>35$ years & 21 & 16.1 \\
\hline Preeclampsia & & \\
\hline No & 120 & 96.8 \\
\hline Yes & 4 & 3.2 \\
\hline Diabetes Mellitus & & 96.8 \\
\hline No & 120 & 3.2 \\
\hline Yes & 4 & \\
\hline TORCH & & 14.5 \\
\hline No & 106 & \\
\hline Yes & 18 & \\
\hline
\end{tabular}

Table 2. Prenatal Risk Factors Analysis Against Cerebral Palsy

\begin{tabular}{|c|c|c|c|c|c|c|c|c|}
\hline \multirow{2}{*}{ Characteristic } & \multicolumn{2}{|c|}{ Cerebral Palsy } & \multicolumn{2}{|c|}{ No Cerebral Palsy } & \multicolumn{2}{|c|}{ Total } & \multirow{2}{*}{ p value } & \multirow{2}{*}{ OR $(95 \% \mathrm{CI})$} \\
\hline & $\mathbf{n}$ & $\%$ & $\mathbf{n}$ & $\%$ & $\mathbf{n}$ & $\%$ & & \\
\hline \multicolumn{9}{|l|}{ Pregnant Mother's Age } \\
\hline$<20$ years or $>35$ years & 19 & 90.4 & 2 & 9.5 & 21 & 100 & 0.00 & 13.25 \\
\hline $20-35$ years old & 43 & 41.7 & 60 & 58.2 & 103 & 100 & & $2.93-59.93$ \\
\hline \multicolumn{9}{|l|}{ Preeclampsia } \\
\hline Yes & 4 & 6.4 & 0 & 0.0 & 4 & 100 & 0.00 & 2.06 \\
\hline No & 58 & 48.3 & 62 & 51.6 & 120 & 100 & & $1.71-2.48$ \\
\hline \multicolumn{9}{|l|}{ Diabetes Mellitus } \\
\hline Yes & 2 & 3.2 & 2 & 3.3 & 4 & 100 & 1.00 & 1.00 \\
\hline No & 60 & 96.7 & 60 & 96.7 & 120 & 100 & & $0.13-7.33$ \\
\hline \multicolumn{9}{|l|}{ TORCH } \\
\hline Yes & 18 & 100 & 0 & 0.0 & 18 & 100 & 0.00 & 2.40 \\
\hline No & 44 & 41.5 & 62 & 58.4 & 106 & 100 & & $1.92-3.01$ \\
\hline \multicolumn{9}{|l|}{ Antenatal Care } \\
\hline$<4$ times & 25 & 96.1 & 1 & 3.8 & 26 & 100 & 0.00 & 41.2 \\
\hline$\geq 4$ times & 37 & 37.7 & 61 & 62.2 & 98 & 100 & & $5.35-317.0$ \\
\hline Total & 62 & 100 & 62 & 100 & 124 & 100 & & \\
\hline
\end{tabular}




\section{Discussion}

The safe age for pregnant women is around 20-35 years because at this age physical, emotional, and psychological readiness is more secure. ${ }^{8}$ Beyond that age can increase the risk of pregnancy and childbirth. Maternal age under 20 years is still too young and immature to undergo pregnancy and childbirth. On the other hand, mothers who are over 35 years of age will experience decline and it is feared that pregnancy and childbirth complications will occur. ${ }^{9}$ National Down Syndrome Society states that there is a relationship between congenital abnormalities and maternal age. Congenital abnormalities are characterized by an excessive number of chromosome number 21 , so that it can cause delays in child development and mental retardation. Congenital abnormalities occur during the first 20 weeks of pregnancy. Situations or events that impair migration and differentiation of the motor cortex, basal ganglia, and cerebellum may be abnormal gene expression or an unfriendly fetal environment resulting from maternal disease, toxicity, infection, or trauma. ${ }^{10}$ This is in line with the study of Schneider et al which stated that mothers who gave birth at the age of $<20$ years had a 2.4 times greater risk of giving birth to children with congenital abnormalities. ${ }^{11}$

One of the complications that can be experienced is neonatal asphyxia in infants $(p=0.02)$ this is because the age 20-35 years is the reproductive age where there has been a maximum readiness for response and it is stated that a mother can safely conceive if she gets good health services during pregnancy, while age less than 20 years or more than 35 years is an age that has a high risk of pregnancy. ${ }^{12}$ This study shows that there is a significant relationship between maternal age at pregnancy $<20$ years or $\geq 35$ years with the incidence of CP in children with $p$ value of 0.00 and OR 13.25. This shows that mothers who conceive at the age below 20 years or over 35 years have a 13.25 times greater risk of having children with CP compared to mothers who conceive at the age between 20-35 years. Ramadhania (2016). ${ }^{9}$ states that pregnant women aged $<20$ years and 35 years have a 12.67 times greater risk of giving birth. children with $\mathrm{CP}$, compared with mothers whose gestational age was 20-35 years, which means that the risk of CP in children increases if the age of the pregnant women is $<20$ years and 35 years.

Preeclampsia is a collection of symptoms of hypertension, edema and proteinuria are sometimes accompanied by convulsions and coma in pregnant women, maternity and childbirth. Preeclampsia that occurs in the mother affects fetal growth and is a risk factor for CP in children Preeclampsia is a collection of symptoms of hypertension, edema and proteinuria are sometimes accompanied by convulsions and coma in pregnant women, maternity and childbirth. Preeclampsia that occurs in the mother affects fetal growth and is a risk factor for CP in children. ${ }^{9}$ Preeclampsia can be caused by a history of hypertension in multiple pregnancies, first pregnancy, kidney disorders, pregnancy less than 20 years or more than 35 years, and poor diet. ${ }^{13}$ Severe preeclampsia in pregnant women can cause death if not treated immediately. it is necessary to be referred to a hospital with a health facility that has the ability to manage obstetric emergencies and newborns immediately. ${ }^{14}$

Preeclampsia has a significant relationship in the incidence of $\mathrm{CP}$ in children where the mothers suffered from preeclampsia during pregnancy 2.06 times more likely to have children with CP compared to mothers who did not suffer from preeclampsia during pregnancy. Balgayeva et al., (2017). suggested that there was a relationship between preeclampsia and the incidence of CP in children $(p=0.04)$. This is in line with Korzeniewski et al., (2018). ${ }^{15}$ which stated that mothers who experienced preeclampsia during pregnancy increased the risk of giving birth to children with CP by 2.4 times greater than mothers who did not experience preeclampsia during pregnancy. In line with Putri (2019). ${ }^{16}$ which obtained results, almost half of the respondents, namely as many as 20 mothers who gave birth to children with $\mathrm{CP}$ had suffered from DM and preeclampsia during their pregnancy.Gestational Diabetes Mellitus (GDM) is a normal pregnancy accompanied by an increase in insulin resistance which is usually experienced temporarily during the second or third trimester of pregnancy. ${ }^{17}$ In GDM, several organs undergo structural changes as well as functional changes such as endothelial dysfunction of micro and macro fetal circulation which can reduce blood flow to the uterus so that it can cause asphyxia and also increase the risk of the baby suffering from CP. In GDM, there is an increased tone of the arteries leading to the uterus through the uteroplacental circulation resulting an endothelial dysfunction that decreasing blood flow to the uterus an acute decrease in uteroplacental blood flow can suddenly threaten the survival of the fetus, while a chronic decrease in uteroplacental flow can cause pathological processes of pregnancy such as preeclampsia and fetal growth restriction. ${ }^{18} \mathrm{We}$ found GDM is not one of significant factors but this result is not consistent with other studies that shows women who suffer from GDM during pregnancy were 1.9 times more likely to have children with CP compared to mothers who did not. ${ }^{11,19,16}$

TORCH infection can attack pregnant women and fetuses in the womb. TORCH is caused by the parasite Toxoplasma gondii, rubella virus, herpes simplex virus type 1 and type 2 . Pregnant women who are infected with TORCH in early pregnancy are at risk of miscarriage, stillbirth, or birth defects such as brain damage, central nervous system disorders, organ abnormalities, birth defects, intellectual disability, and developmental delay. ${ }^{20,21}$ The prevalence of TORCH infection in Indonesia is quite high, ranging from $5.5 \%$ to $84 \%$. In $67 \%$ of women with TORCH infection, $13.8 \%$ had Rubella, $10.3 \%$ had Toxoplasma and $13.8 \%$ had Cyto megalo virus. TORCH infection in pregnant women can cause congenital abnormalities in the fetus by $5-10 \%$. Congenital abnormalities can attack all organs of the body and can cause hearing, vision, and metabolic disorders. TORCH infection can be prevented with the TORCH vaccine obtained before marriage or several months before the pregnancy program so that the vaccine can work to protect the body optimally. ${ }^{20,21,22}$ 
TORCH increases the risk of 2.40 times greater to have children with CP. Previous research has also shown TORCH during pregnancy is 3.8 times more likely to have a child with CP.23 Sost mothers of children with $\mathrm{CP}$ have a history of TORCH $(41.67 \%) .^{21}$

Antenatal care is health care to monitor and maintain the health of the mother and fetus during pregnancy, childbirth and postpartum in the form of early detection of risk factors, prevention and treatment early complications that may occur. ${ }^{24}$ antenatal care can prevent the occurrence of CP in children, while antenatal care visits that are less than 4 times will increase the risk of complications during pregnancy, childbirth and the puerperium. ${ }^{21,25}$ There are several factors that affect antenatal care visits as factor knowledge of mothers about the importance of antenatal care visits will have an impact on the attitude and behavior of mothers to antenatal care visits regularly. The role of health services also plays a role as one of the factors for pregnant women to visit antenatal care, adequate health service facilities will make pregnant women make regular visits. Providing information related to the importance of antenatal care visits will affect the knowledge, attitudes and behavior of pregnant women. ${ }^{26,27}$ Based on the results of the analysis, it was found that mothers who had less than 4 antenatal care visits were 41.2 times more likely to have children with CP compared to mothers who had 4 or more antenatal care visits. Mothers who made antenatal care visits less than 4 times had a 1.86 times greater risk of causing disability in children such as CP. ${ }^{28}$

There are several limitations in this study. such as ruling out other prenatal risk factors such as gene abnormalities, rhesus blood group differences between mother and baby, fetal stroke. Data on patients and risk factors for CP in Indonesia is still minimal, so there are references from other countries that may have different backgrounds.

\section{Conclusion}

Variable age of pregnant women $<20$ years or $>35$, pregnant women suffering from preeclampsia, pregnant women suffering from TORCH, and antenatal care visits $<4$ times are risk factors for Cerebral Palsy in children. Meanwhile, diabetes mellitus is not a risk factor for Cerebral Palsy in children. It is necessary to improve intervention programs at various levels of health care especially at first-level health facilities to provide basic health services to mothers and children to prevent cerebral palsy in children in the future so as to achieve optimal maternal and child health. And further research is needed to determine other risk factors that may cause CP in children such as perinatal and postnatal risk factors.

\section{Acknowledgement}

The author would like to thank to those who have helped the research, namely RSIA Bunda Jakarta, which has provided access to retrieve respondent data. Thank you to the reviewers who have provided input and suggestions to make this article even better.

\section{Conflict of Interest}

The author stated there is no conflict of interest

\section{References}

1. Puteri IR, Antasari F. Factors Influencing Developmental Disorders of Cerebral Palsy. Indonesia Science Health Journal. 2016.

2. Riskesdas. Basic Health Research 2010. Riskesdas 2010.

3. Purnomo D, Kuswardani K, Novitasari R. The Effect of Exercise Therapy on Increasing Functional Ability in Cases of Diplegia Spastic Cerebral Palsy. Journal of Physiotherapy and Rehabilitation. 2018;2(1):1-8.

4. Sitorus FSAB, Mogi T isye, Gessal J. Prevalence of Children with Cerebral Palsy in Medical Rehabilitation Installations at RSUP.Dr.R.D. Kandou Manado 2015. Clinical Medicine Journal. 2016;1(1):14-9.

5. Sadowska M, Sarecka-Hujar B, Kopyta I. Cerebral palsy: Current Opinions on Definition, Epidemiology, Risk Factors, Classification and Treatment Options. Neuropsychiatric Disease and Treatment. 2020;16:1505-18.

6. Trisnowiyanto B, Purwanto Y. Prenatal, Perinatal and Postnatal Risk Factors for Cerebral Palsy. Integrated Journal of Health Sciences. 2019;8(2):204-9.

7. Salfi QN, Saharso D, Atika A. Profile of Cerebral Palsy Patients in Dr. Soetomo General Hospital Surabaya, Indonesia. Biomoleculer and Health Science Journal. 2019;2(1):13.

8. Kemenkes RI. Regulation of the Minister of Health of the Republic of Indonesia Number 97. Kemenkes RI. 2014.

9. Ramadhania NN. Prenatal Risk Factors for Cerebral Palsy. Thesis, Faculty Medice Airlangga University. 2016.

10. Rayman R, Rahmanisa S, Putri GT, Kedokteran F, Lampung U, Molekuler BB, et al. Relationship Age of Mother with Syndrome Down Symptoms. Journal Medula. 2017;7:144-8.

11. Schneider RE, Ng P, Zhang X, Andersen J, Buckley D, Fehlings $\mathrm{D}$, et al. The Association Between Maternal Age and Cerebral Palsy Risk Factors. Pediatric Neurology. 2018;82:25-8.

12. Lubis TEF, Batubara NS. Factors Related to the Incidence of Asphyxia Neonatorum in Infants at the South Tapanuli District Hospital in 2018. Indonesia Science Health Journal. 2020;5(1):27-35.

13. Aprilia W. Development during Prenatal and Birth. Yaa Bunayya Journal of Early Childhood Education. 2020;4(1):40-55.

14. Adeline ME, Laksana MAC, Atika S. Characteristic of Referral Patients With Severe Preeclampsia In Surabaya. Biomoleculer and Health Science journal. 2018;1(1):25.

15. Korzeniewski SJ, Slaughter J, Lenski M, Haak P, Paneth N. The Complex Aetiology of Cerebral Palsy. Nature Reviews Neurology. 2018;14(9):528-43.

16. Putri SMAP, Kurniawan CD, Silakarma D. Prenatal, Perinatal, and Postnatal Factors of Cerebral Palsy in Children. Udayana Medika Journal. 2019;8(8):2-7.

17. Mutia MS. Risk Factors for Perinatal Death in dr. Pirngadi Hospital Medan.MIPA Education Research Journal. 2018;3(1):208-16.

18. Isngadi, Sindharta R, Uyun Y, Rahardjo S. The Effects Of Gestational Diabetes Mellitus To Uteroplasental Circulation. Jurnal Anestiologi Indonesia . 2016;7(2):22-33.

19. Yuan J, Wang J, Jieqiong MA, Zhu D, Zhang Z, Li J. Paediatric Cerebral Palsy Prevalence and High-Risk Factors in Henan Province, Central China. Journal Rehabillitation Medice. 2019;51(1):47-53.

20. Dewi R. Pregnancy with TORCH Infection. Lampung University Health Journal. 2019;3(1):176-81.

21. Sulistyawati N, Mansur AR. Indication of Causative Factors and Signs and Symptoms of Children with Cerebral Palsy. Husada's Health Journal. 2019;7(1):76-87.

22. Chrinstin MCM. Description Of Knowledge Level and Torch Infection Prevention Measures (Toxoplasmosis, Rubella, Cytomegalovirus, Herpes Simplex Virus) in Women of Women Of Reliable Age in The Community of Cat Lovers in West Kalimantan 2015. Thesis from Faculty Media tanjaungpura University pontianak. 2016;1-27.

23. MacLennan AH, Thompson SC, Gecz J. Cerebral palsy: Causes, Pathways, and the Role of Genetic Variants. A American Journal of Obstetrics and Gynecology. 2015;213(6):779-88.

24. RI K. Indonesia Health Profile 2019. Kemenkes RI. 2019.

25. Siwi RPY, Saputro H. Analysis of Factors Affecting the Low 
Integrated Antenatal Care (ANC) Visits for Pregnant Women in the Working Area of Sukodono Health Center, Lumajang Regency. Journal for Quality in Women's Health. 2020;3(1):2230 .

26. Fitrayeni F, Suryati S, Faranti RM. The Cause of the Low Completeness of Antenatal Care Visits for Pregnant Women in the Work Area of the Pegambiran Health Center. Andalas Public Health Journal. 2017;10(1):101.

27. Dharmayanti I, Tjandrarini DH, Hidayangsih PS, Nainggolan O. The Influence of Environmental and Socio-Economic Health Conditions on Mental Health in Indonesia. Journal Health Ecology. 2018;17(2):64-74.

28. Safitri HO. Determinants of low birth weight in Indonesia. Thesis Faculty Nursing, Airlangga University. 2019. 